\title{
Climate Change: A Growing Challenge for Water Management in Developing Countries
}

\author{
P. P. Mujumdar
}

Received: 2 September 2011 / Accepted: 22 November 2011 /

Published online: 28 December 2012

(C) Springer Science+Business Media Dordrecht 2012

Water managers today are faced with the daunting task of evolving management strategies and policies in the face of not only the large uncertainty associated with the climate change impacts but also, to some extent, a sense of perplexity and confusion that the issue of climate change seems to have created because of conflicting views, opinions and even scientific projections on the impending regional water situations. Such a sense of confusion is particularly pronounced in the developing countries, where the capacity to understand the different issues of climate change as it affects the water systems is extremely limited among water managers. They are aware that they must cope with abnormal situations more frequently than they used to, that the future is not likely to be similar to the past and that therefore they need guidance from the scientific community in dealing with the evolving situation. Even a small part of the huge amount of scientific work dealing with impacts on water availability, water demands, water quality and frequencies and magnitudes of floods and droughts has, however, not yet found its way into policy interventions and decision making.

Impact studies relevant to water resources management address situations of decreasing water supply and simultaneous increase in water demands. Downscaled projections of temperature, precipitation, windspeed, relative humidity and net radiation are typically used for assessing the future irrigation (and other) water demands; projections of streamflow, obtained either directly by downscaling or through use of a hydrologic model, are used in assessing impacts on the water supply and water quality. The ensemble approach that uses climate simulations from a large number of models for several future scenarios is commonly used to address the model and scenario uncertainties. Use of hydrologic models in impact studies in river basins brings along an additional source of uncertainty due to the usually large number of parameters calibrated based on limited historical data, and assumed stationarity over the future period. Such uncertainties at all levels of impact assessmentfrom climate models to emission scenarios, downscaling and hydrologic models - seem to discourage the water managers from using the results of climate impact studies. Additionally, the impacts and adaptive responses are generally provided for a far-distant time

P. P. Mujumdar $(\bowtie)$

Indian Institute of Science, Bangalore, India

e-mail: pradeep@civil.iisc.ernet.in 
window, such as the 2040 s or 2060 s, which do not enthuse the water managers whose goals are often driven by short term considerations. The responsibility of the scientific community therefore, must be to address the question of reducing uncertainty in the impact assessment and to provide near-future decadal projections for use in water management policies. The CMIP5 ensemble of climate models has opened up a new possibilityof obtaining near-future decadal projections.

Developing countries are also faced with the challenge of meeting increasing urban water demands. Urban water systems require a different degree of scientific expertise than riverbasin scale water systems. The immediate impact of climate change on urban water supply systems is through altered surface and ground water resources, because of possible reduction in streamflow and rainfall. In many cities, an over-reliance on groundwater has put that resource under stress already. Another important effect of climate change, often ignored in the impact studies, is an increase in urban water demand because of rise in temperature, even not accounting for the increase in population. Additionally, increasing intensities of rainfall along with unplanned development of cities exacerbate the already critical urban flooding problem and stress the urban water infrastructure. Urban floods are caused by short duration high intensity rainfall, which are projected to increase in many regions-but the overall water availability is governed by the seasonal rainfall, which may be decreasing; in fact, these two situations - increase in high intensity, short duration rainfall and decrease in total amount of seasonal rainfall - do occur together in many cities. In such situations, operation and maintenance of urban water systems becomes particularly challenging.

In rapidly developing countries, such as India, the current emphasis on creation of large scale water infrastructure must be augmented with well-formulated adaptive policy options. Indeed, the issue of climate change offers an enormous opportunity to such countries to apply corrections to the poorly managed water systems. In building resilient, adaptive responses, out-of-the-box solutions synthesising the Gandhian and the Schumaker 'small is beautiful' perspective with that of large scale engineering interventions will be necessary. Measures such as reviving the village tanks, adopting small-scale, local rainwater harvesting and recycling of waste water should be integrated into the large scale engineering and management solutions of improving irrigation efficiencies, increasing storage and allied infrastructure, harnessing flood waters as a resource, changing the cropping patterns and irrigation practices and desalination of seawater to build resilience into water management systems. The groundawater reservoir should be recognised as an insurance against drought and it adds to the resilience of a water resource system. The response of groundwater to climate variability and change is also likely to be much slower and less critical compared to that of surface water. More emphasis needs to be placed therefore on evolving conjunctive use policies as options for resilient response to climate change.

The papers presented in this issue discuss many relevant questions on developing resilient response to climate change. Water systems, by their very nature, call for an inter-disciplinary perspective in analysis, as the systems affect, influence, enthuse and benefit a large number of stakeholders from farmers to domestic users, from government agencies to private enterpreneurs and from engineers and social scientists to economists and ecologists, among others. This special issue, consisting of well-thought out collection of articles from leading experts from different fields, provides a very useful reference material for both the water managers and the scientists. 